Journal of Management Studies 56:8 December 2019

doi: $10.1111 /$ joms. 12289

\title{
Evolving Reactions: 60 Years with March and Simon's 'Organizations'
}

\section{Karl E. Weick}

University of Michigan

In their book titled 'Organizations'. March and Simon (1958) aspired to 'replace fancy with fact in understanding the human mind and human behaviour in an organizational setting' (p. 210). The question of the continuing influence of that book 60 years later becomes more interesting when we ponder two contrasting viewpoints. Thoenig (1998) suggested that 'Science as an institutionalized activity usually helps the past to survive and hinders the potential for the future to become visible and legitimate' (p. 311). Does the recognition of a book that is 60 years old somehow hinder equivalent development of understanding in the next 60 years? Probably not. This holds true if we follow Davis's (2010) suggestion that progress in organizational theory means 'making comprehensible the developmental pathways of organizations and organizing ex post... (In other words) rendering the ecosystem comprehensible'. The goal is not so much precision in predictions as it is 'insights into particular processes at particular times' (p. 707). M\&S consolidated insights and predictions that continue to help rather than hinder the ongoing development of understanding. This becomes evident as we move from the book's modest early reception in the late 50 s to the ways in which it 'became' more insightful as fancies flourished and then folded over the last 60 years. M\&S remained a durable set of foundations.

My experience with 'Organizations' started when I first studied it as a Psychology graduate student, 6 months after the book was published (February 1959). I restudied the book in the context of its deserved recognition 60 years later (June 2017). I liked the book more in 2017 than I did in 1959. I briefly describe both sets of reactions.

\section{ZEITGEIST OF THE 1950s}

The context in which 'Organizations' first appeared was one of diffuse social science that was being consolidated and gaining momentum (e.g., Koch, 1959). For example,

Address for reprints: Karl E. Weick, Ross School of Business, University of Michigan, 701 Tappan Street, Ann Arbor, MI 48109-1234, USA (karlw@umich.edu). 
four years earlier the monumental two volume 'Handbook of Social Psychology' (Lindzey, 1954) first appeared with significant discussions of field theory, cognitive theory, group problem solving, and industrial social psychology. All of these topics were now available to be edited into organizational studies. The closest discussion to March and Simon (hereafter M\&S) in the Handbook was Mason Haire's chapter on 'Industrial Social Psychology'. M\&S found that the chapter made only 'passing references to organizations' (p. 2).

Books were the primary form of consolidation in the 50s and 60s (Colquitt and Zapata-Phelan, 2007). This gave authors space to discuss relevant issues and puzzles and to speculate. Outlets for journal-length articles were limited. ASQ was only 2 years old. AMR, AMJ, Organizational Science, and Organization Studies did not yet exist. Social Psychology was lumped with abnormal psychology in the Journal of Abnormal and Social Psychology.

In the late 50's there was considerable popular discussion of the ways in which employers shaped mature adult employees toward less mature dependency, conformity, and compliance (e.g., The Organization Man, Whyte, 1956). Chris Argyris brought a scholarly mindset to these issues as represented by his well-known 1957 book, 'Personality and organization; the conflict between system and the individual'. Argyris earned his $\mathrm{PhD}$ in 1951 under his advisor William F. Whyte and began publishing research on bank organizations and how their control systems affected employees. Although the topic of individual 'vs.' organization was timely, it was not central for M\&S. In their words, employees 'come to an organization with a prior structure of preferences, a personality if you like' (p. 65).

The approach used by M\&S gained momentum a year after the book's publication when both the Ford Foundation and the Carnegie Foundation took an interest in business education. The reports they commissioned called for more research and less consulting work by faculty, improved regulation, fewer case studies, more theory and analysis, and more teaching of ethics (Hutchins, 1960). These appeals for change and more rigour were realized and exemplified in the propositions, formalization, and grounding displayed a year earlier in 'Organizations'.

Networks, a topic that seems to have been with us forever, was no less prominent in 1958. The difference was that networks in the 50s were concrete rather than abstract, were situated in laboratories rather than in the field, and consisted of partitions that separated actors who could communicate with one another by passing notes through slots in their partitions. Active researchers such as Harold Guetzkow, Herbert Simon, Marvin Shaw, Harold Kelley, Alex Bavelas, and Harold Leavitt all studied these simulacra of the real world. Most of these researchers made conservative interpretations of their findings. This meant that structural explanations were more prominent than processual ones. And the structures that were attributed to organizations tended to be elementary (e.g., star, circle, wheel).

Finally, decision-making also seems to have been with us forever. In the late 50 s there was a stimulating contrast between a focus on pre-decision and post-decision behaviour. M\&S articulated a prospective view of decision-making in which pre-decision activities were influential. Festinger (1957) and his associates articulated a very different retrospective view of decision-making in which post-decision behaviour was what mattered. 
The point is simply that decision-making was a centre of attention in the $50 \mathrm{~s}$. M\&S demonstrated that there were strong alternatives to the rationalist perspective imported from economics.

\section{FIRST IMPRESSIONS}

Given this Zeitgeist, I want to recount several first impressions formed in February 1959, 6 months after the book was published. The book was assigned in a graduate psychology seminar taught by a professor who was excited about the book's aspirations to carve out a new field. As I mentioned above, M\&S stated that their goal was to 'replace fancy with fact in understanding the human mind and human behavior in an organizational setting' (p. 210). The book did that, although not immediately for a subset of us in the seminar. We had several reactions that were less enthusiastic than those of the professor. Remember, these reactions emerged in a psychology seminar, taught in a behaviourist-inclined Psychology department (Ohio State University), a department that had only one social psychologist (Lauren Wispe; not the 'excited professor').

The first reaction among our subset was, 'This is basically stimulus-response psychology'. That was not altogether inaccurate since the authors described their work this way: "We will speak of the "stimuli" that impinge on the individual, of the psychological "set" or "frame of reference", that is evoked by these stimuli, and of the "response" or "action" that results' (p. 35). However, with a closer look years later, it is clear that M\&S deepened this starting point when they identified 'pathologies' associated with the stimuli such as their evocation of unanticipated associations, their unanticipated provision of additional stimuli, and their failure to evoke the anticipated set (p. 35). Clearly, this was not just warmed over SR theory.

The second reaction was one of anxiety: 'Apparently, we're not as smart as we think we are'. M\&S rendered the human organism as a 'choosing, decision-making, problemsolving organism that can do only one or a few things at a time, and that can attend to only a small part of the information recorded in its memory and presented by the environment' (p. 11). The emphasis on simplification, satisfactory performance, and cognitive limits, while sobering, was in fact closer to the experienced real world of the overloaded grad student than were rational man and optimizing. Satisficing felt like a more meaningful shortcut through classical rationality.

A third reaction was, 'Many of these propositions seem obvious'. For example, 'increases in the balance of inducement utilities over contribution utilities (4.1) decreases the propensity of the individual participant to leave (4.2) the organization' (p. 93). People whose inducements greatly exceed their contributions are likely to stay put. However, obviousness was not the liability that we thought it was. Propositions that appear obvious may be easily forgotten (M\&S, p. 58) and contribute undetected variance to outcomes. What looked 'obvious' to us misread the fact that M\&S were focused on the development of recurrent behaviours, routines, and habits. While early stages of routinization look non-routine, later stages look more patterned and automatic, thus, more obvious. Furthermore to call something obvious may confuse common-sense obviousness with unimportance (p. 143). As M\&S put it, when there is no 'surprise' in a scientific prediction, that is not much different from predicting 'the lines that will be 
uttered by a Hamlet on stage. It is no less important for its common - sense obviousness' (p. 143). I confess to often conflating unimportance with obviousness but, 60 years of immersion in organizational studies has convinced me that very little is obvious or obviously unimportant.

A fourth reaction was, 'some of the cited works sounded just as interesting as M\&S'. This redirected some readers to those works and away from M\&S. For example, a short but rich quotation from Chester Barnard on approximation (p. 190), led to the swift formation of a reading group to study Barnard's (1938) 'Functions of the Executive'. That diversion was not as 'disloyal' as it may sound since a central citation in M\&S is the Barnard-Simon equilibrium theory of organizational survival (pp. 83-89). A different example of reading elsewhere was M\&S's brief discussion of Robert Merton's theory of unanticipated consequences (pp. 37-40). Most of us in the seminar were fascinated by the idea that there were orderly but unintentional progressions by which people got into trouble, progressions that arose from situational complexity and selective perception. These progressions looked a lot like what Merton (1948) had earlier called self-fulfilling prophecies.

A fifth reaction was one of being overwhelmed by the book itself. That was partly because we were accustomed to narratives about organizations (e.g., Whyte, 1948) rather than to lists of variables. And the list in M\&S was very long. They presented their argument in the form of 206 variables (these 206 are indexed on pp. 249-53). The largest number of variables, 88, is found in Chapter 3 on 'Motivational constraints: intraorganizational decisions'. The fewest number of variables are in chapter 5 (26 variables in 'Conflict in organizations') and chapter 7 (28 variables in 'Planning and innovation'). The authors imposed order on these variables in two ways. First, they tried to separate them by means of 3 sets of assumptions: employees are passive; employees bring attitudes, values and goals into the organization; and employees rely on thought and perception processes embedded in decision-making and problem solving (p. 6). Second, they tried to link these variables using 3 types of propositions: those with an independent and dependent variable; those that involve a qualitative generalization (e.g., Organizations try to routinize new activities); and those that propose that a specific structure or process performs a specific function (e.g., rigid behaviour makes action defensible) (pp. 7-8).

A sixth reaction was that, unlike Festinger's (1957) recently published 'Theory of Cognitive Dissonance', it was hard to see where or how to enter M\&S's ideas. Festinger was focused on two cognitions held simultaneously with one being the obverse of the other. M\&S, by contrast, were more eclectic, more multidisciplinary, more likely to move among multiple levels of analysis. This difference between the two sets of scholars recapitulates the classic differences between breadth and depth or foxes and hedgehogs (Berlin, 2013). The value of M\&S's fox-like breadth and avoidance of a single idea makes it harder to envision a next meaningful step in working with their ideas. That difficulty, however, seems mitigated in work since 1958. For example, current work on the flexibility with which routines are enacted (e.g., Feldman, 2000) is anticipated when M\&S observed that routine performance programmes are often better understood as 'performance strategies' (p. 142).

A $7^{\text {th }}$ reaction involved what would now be called the 'optics' of M\&S. Their model was composed of short links in long sequences. The problem was, some sequences had 
feedback loops and mutual causality but others didn't. Sequences without feedback (e.g., Figure 3.7, p. 64) suggest a more passive individual who is subject to multiple influences with little control (see Kilduff, 1993). Relationships of mutual causality (e.g., Figure 3.8, p. 68) make it easier to conceptualize agents and structure as mutually constitutive. The problem was that the two halves of the 'Organizations' book differed in the prominence of these causal structures. In the first 66 pages, seven of the eight figures with connected variables contained feedback loops. These pages are focused mainly on organizational studies up to 1957. From then on (pp. 67-154) M\&S's model is the focus and none of the eight figures contained feedback loops. There was no mechanism for control or enactment.

Before moving on to reactions that are more contemporary, I wonder if our seven reactions to M\&S in a 1959 seminar persist, in generic form, when graduate students in 2017 dig into organizational studies? Do they too feel that some of what they examine is older wine in new bottles, sobering, obvious, better said elsewhere, overwhelming, elusive, and constrained by formatting? Probably not since current explanations tend to be more specialized, more focused, more narrow, more problem-driven, more insistently macro or micro and less meso (e.g., Davis and Marquis, 2005).

\section{GURRENT IMPRESSIONS}

Unable to find my original copy of 'Organizations', I bought a used copy that had only one sentence underlined in the entire book. That sentence read, 'In the absence of empirical evidence little can be said about these propositions except that they conform to our own experience and intuitions' (p. 104). That sentence must have greatly impressed the reader because he or she recopied it, word for word, in large letters, inside the back cover of the book. What's going on here? Is this a summary of the reader's reaction to the book, in the language of the book? A reminder of a model to be followed in the reader's own work? Foresight into what the field of organizations would continue to be? Perhaps even indirect guidance for a career move (the sentence appears in Section 4.6 devoted to 'factors affecting the perceived ease of movement from the organization' (pp. 100-06)?

Evidence, intuitions, experience. We need all three. But, in what proportion? In restudying M\&S there are many ideas that seem to fuse all three. I briefly point out three of these: bounded rationality, reification, and mosaic forms.

\section{BOUNDED RATIONALITY}

One of the more enduring notions from 1958 is the concept of bounded rationality (e.g., Kahneman, 2003). However, if you look for the phrase 'bounded rationality' in the book, you won't find it. What you will find is the phrase 'boundaries of rationality' (p. 169). That more inclusive phrase implies that limits are not confined solely to individuals. Instead, as M\&S emphasize, boundaries of rationality 'are elements of the situation that must be or are in fact taken as givens and that do not enter into rational calculations as potential strategic factors. If there were not boundaries to rationality, or if the boundaries varied in a rapid and unpredictable manner, there could be no stable organization structure' (pp. 170-171, italics added). These boundaries certainly include 
'the properties of human beings as organisms capable of evoking and executing relatively well-defined programs but able to handle programs only of limited complexity'. (p. 171). But 'boundaries of rationality' suggests a broader set of limiting conditions. As Fine (1991) puts it, 'The world's fastness and vastness constrains micro through material reality, time, space, power, history, and organizations' (p. 172).

M\&S incorporate boundaries of rationality into a 'phenomenological viewpoint' (p. 138) when they state that one can only speak of rationality relative to a frame of reference. This becomes evident in their claim that 'The definition of the situation represents a simplified, screened, and biased model of the objective situation and filtering affects all of the "givens" that enter into the decision process: knowledge or assumptions about future events; knowledge of sets of alternatives available for action; knowledge of consequences attached to alternatives; goals and values' (pp. 154-5). This brings to mind Barry Turner's compact assertion that organizations accomplish coordination in part by inducing their managers to agree that they will all neglect the same things when they make decisions. 'Certain possibilities, issues and contingencies are important and relevant in organizational decision making, while other possibilities, issues and contingencies may be ignored without incurring official disapproval' (Turner and Pidgeon, 1997, p. 166).

The idea of bounded rationality survives to this day in a variety of forms. One example is the concept of 'thin rationality': Actors in most cases do things for a reason (Bengtsson and Hertting, 2014, p. 708). Thin rationality is further elaborated with the description that 'Actors are "trying to reach their goals within the limits of their perceived scope of action... This is the logic of action behind all mechanisms... Only assume that actors behave in accordance with the situation and its logic and nothing else"' (pp. 714-5).

Boundaries of rationality also survive in much richer form in Farjoun and Starbuck's (2007) insightful analyses of limits. 'Both organizations' successes and failures depend on their abilities to exceed only those limits they choose to exceed and to remain within other limits' (p. 563). The parallels between a focus on limits and on boundaries of rationality is striking. 'The focus on limits reminds researchers that, in real time, decision-makers' actions face multiple and inconsistent goals, incomplete information, ambiguous feedback, and many potential futures. As a result, intended actions produce outcomes, such as discoveries or accidents, that were unintended or random. This decoupling of actions and outcomes not only complicates rational action in organizations, but also limits the ability of observers - analysts, researchers, regulators, journalists or members of investigation boards - to assign blame and credit' (p. 562).

\section{REIFICATION}

My favourite sentence in the M\&S book is this one: 'The reification of the organization's conceptual scheme is particularly noticeable in uncertainty absorption' (p. 165). Here's why that's my favourite. It is a compact description of a cognitive perspective on organizational life. Perceptions are edited into concepts. Concepts edit perceptions. Organizations attempt to constrain decision-making by valuing a handful of concepts (conceptual scheme); by socializing employees to see the world as embodied in those concepts (reification); and by relying on those reifications to absorb uncertainties for people facing flux 
on behalf of the organization. In the basic M\&S argument, inferences are drawn from evidence and the inferences rather than the evidence itself are communicated.

What gets communicated by ongoing reification may seem stable but it is dangerous and can lead to what James (1987) called 'vicious abstractions'. 'We conceive a concrete situation by singling out some salient or important feature in it, and classing it under that; then, instead of adding to its previous characters all the positive consequences which the new way of conceiving it may bring, we proceed to use our concept privatively; reducing the originally rich phenomenon to the naked suggestions of that name abstractly taken, treating it as a case of "nothing but" that concept, and acting as if all the other characters from out of which the concept is abstracted were expunged. Abstraction, functioning in this way, becomes a means of arrest far more than a means of advance in thought' (p. 951). It is these 'means of arrest' that establish the stability of organizations but in doing so foreshadow the organization's diminished adaptation and accelerated decline.

M\&S echo James's commentary when they observe that the technical vocabulary and classification schemes in an organization provide a set of concepts that can be used in analysing and communicating about its problems. 'Anything that is easily described and discussed in terms of these concepts can be communicated readily in the organization: anything that does not fit the system of concepts is communicated only with difficulty, hence, the world tends to be perceived by the organization members in terms of the particular concepts that are reflected in the organization's vocabulary. The particular categories and schemes of classification it employs are reified, and become for members of the organization attributes of the world rather than mere conventions' (pp. 164-5).

In an effort to call attention to reification and reduce it, I naively counselled theorists to 'stamp out nouns' (Weick, 1979, p. 44). I wanted descriptions that were more attuned to impermanence and to process, flows, reaccomplishment, and emergence. Misplaced concreteness was the villain. Bakken and Hernes (2006), however, disagreed and returned more to the spirit of M\&S by virtue of their close reading of Whitehead. True, there is a danger of misplaced concreteness 'when nouns begin to live their own lives, separated and disconnected from the process that created them... (But) nounmaking is an indispensable ingredient for coming to grips with processes, the point being that we make nouns from processes in order to make sense of processes... we freeze processes into entities, precisely in order to make sense of the fluid, "real" world' (Bakken and Hernes, 2006, pp. 1601-2).

\section{THE MOSAIC FORM}

'Modules' and 'programmes' are prominent nouns in 'Organizations'. Equally prominent are portrayals of organizational fragments. These portrayals describe sub-units as self-contained, loosely coupled, segmented, departmentalized, decentralized, all of which represent a composite organization (p. 195). The prevailing image is one of tight, self-contained, loosely connected units. This image resembles that of a mosaic, as M\&S notice: 'The whole pattern of programmed activity in an organization is a complicated mosaic of programme executions, each initiated by its appropriate program-evoking step' (p. 149, italics added). As they say further on, 'Since there are limits on the power, 
speed and capacity of human cognition, most human behavior in organizations is constituted by a "mosaic of programs" (p. 172, italics added).

The image of a mosaic is shorthand for the observation that units, of whatever kind, are tight within and loose between. This insight, eventually expanded into the idea that organizations are loosely coupled systems (e.g., Glassman, 1973; Orton and Weick, 1990), was anticipated when M\&S discussed simplification. When people with cognitive limits encounter complex problems, they scale down their action programs. '(E)ach action program is capable of being executed in semi-independence of the others - they are only loosely coupled together' (p. 169).

In a mosaic the whole does not precede the parts. Instead, the whole is a collection of parts that don't lose their individuality when connected. In an interesting phrasing, M\&S observe that it takes efficient communication to 'tolerate interdependence' ( $\mathrm{p}$. 162). This is one reason why M\&S are able to get so much mileage out of concepts anchored in individual behaviour. Organizations aggregate 'very large numbers of elements, each element, taken by itself, being exceedingly simple' (p. 178). The working assumption seems to be that an organization is a mosaic of loosely coupled subunits whose members are more or less likely to invoke a shared mental set when assigned a task. Said differently, organizations can be portrayed as differentiated tight modules connected loosely by influence processes. There is a timeless quality to this basic pattern which accounts, in part, for its continuing relevance.

For example, the basic pattern is evident in Simon's (1962) 'empty world hypothesis' most things are only weakly connected with most other things (p. 111). That pattern of tight within stable sub-assemblies and loose between them, was evident in 1958 when M\&S discussed planning (pp. 176-7). If the world is empty and most events are unrelated to other events, then local changes in action programmes are sufficient. However, even in a mostly empty world, there are still minimal connections among programmes since 'they all draw upon the resources of the organization' (p. 176). As Simon was to put it later, 'for a tolerable description of reality only a tiny fraction of all possible interactions needs to be taken into account. By adopting a descriptive language that allows the absence of something to go unmentioned, a nearly empty world can be described quite concisely. Mother Hubbard did not have to check off the list of possible contents to say that her cupboard was bare' (p. 473).

\section{SUMMATION}

I have described a handful of reactions to M\&S that evolved over 60 years. There are at least three ways to put a frame around these reactions and add coherence to the discussion. These three frames focus on classics, shoulders, and fish-scales.

One way to interpret the preceding reactions is to invoke a protocol often used to assess classics, namely, Stinchcombe's (1982) discussion of six functions of classic work. Those six functions are (1) touchstone (the classic demonstrates what work should look like if it is to make a contribution); (2) complexification (classic induces deeper thinking); (3) intellectual small change (classic serves as a badge that signifies what the author is up to); (4) source of fundamental ideas (classic suggests ways to work backward toward more basic ideas); (5) underexploited normal science (classic supplies puzzles for daily 
scientific work); and (6) ritual (classic holds intellectual community together by affirming a common history).

M\&S serve all six of these functions for scholars of organizational studies, but that is not necessarily true for individuals. My reactions suggest that $\mathrm{M} \& \mathrm{~S}$ is valuable to me as a touchstone (it's a model of synthesis, consolidation); complexification (my current re-reading complicates my ideas about sense-making and organizing for high reliability); and source of fundamental ideas (the three 'current impressions' in this essay illustrate this usage). I make less use of M\&S as small change (I am unlikely to present my work as aligned with the Carnegie School), or as a guide to normal science (that's not a problem when doing armchair ethnography), or as a ritual (I find it hard to locate people with a 'common history').

A second way to frame the preceding reactions is to invoke Newton's familiar assertion, 'If I have seen further, it is by standing on the shoulders of giant' (Merton, 1998). What remains ambiguous is whose giant shoulders scholars of organization stand on. The shoulders seem to range among stars, mavericks, sages, peers, shamans, laureates, tribes, stylists. This is not to trivialize Newton. Instead, it is to render his observation more problematic and more attractive as a target of inquiry. Perhaps 'giants' are no longer a meaningful category since, to press the metaphor, people standing on shoulders may see farther but, in response, cumulation becomes of secondary importance and history becomes defined as work done in the last 10 years. We do need to recall that in the earliest versions of the image, dwarfs were standing on those giant shoulders.

In my case I stand on M\&S shoulders because they provide insight into intuition and simplification, alternatives to rationality, coping with uncertainty, groups of groups, and configurations of loosely coupled units whose identities are more visible because they are more tightly coupled within.

A third way to frame the preceding reactions is provided by Campbell's (1969) 'fishscale model of omniscience'. 'The slogan is collective comprehensiveness through overlapping patterns of unique narrowness. Each narrow specialty is in this analogy a fishscale... (O)ur only hope of a comprehensive social science, or other multiscience, lies in a continuous texture of narrow specialties which overlap with other narrow specialties' (p. 328). My reading of M\&S is that their 'propositional inventory' takes several novel narrow fragments, illustrates their adjacency, and in doing so creates overlaps where there had previously been gaps. The result moves social science and organizational studies toward 'collective omniscience'.

In their preface to the 2nd edition of Organizations published in 1993 the authors, looking back over 35 years, remarked that 'although the central construct is decisionmaking, much of the theory developed in the book is less a theory of choice than a theory of attention' (March 2008, p. 36). My commentary implicitly has been more about attention than choice. More importantly, my reactions have evolved to the point where Organizations (1958) is both a giant set of shoulders and an enduring source of collective omniscience. Those results occurred because the book fused evidence, experience, and intuition. That fusion makes the book truly a touchstone.

\section{AGKNOWLEDGMENT}

The author acknowledges, with deep appreciation, the valuable comments of William Starbuck and Phillip Bromily on an earlier draft of this commentary. 


\section{REFERENGES}

Bakken, T. and Hernes, T. (2006). 'Organizing is both a verb and a noun: Weick meets Whitehead'. Organization Studies, 27, 1599-616.

Barnard, C. I. (1938). The Functions of the Executive. Cambridge, MA: Harvard University.

Bengtsson, B. and Hertting, N. (2014). 'Generalization by mechanism thin rationality and ideal-type analysis in case study research'. Philosophy of the Social Sciences, 44, 707-32.

Berlin, I. (2013). The Hedgehog and the Fox: An Essay on Tolstoy's View of History. Princeton, NJ: Princeton University Press.

Campbell, D. T. (1969). 'Ethnocentrism of disciplines and the fish-scale model of omniscience'. In Sherif, M. and Sherif, C. W. (Eds), Interdisciplinary Relations in the Social Sciences, Chicago, IL: Aldine, 328-48.

Colquitt, J. A. and Zapata-Phelan, C. P. (2007). 'Trends in theory building and theory testing: A five-decade study of the Academy of Management Journal'. Academy of Management Fournal, 50, 1281-303.

Davis, G. F. (2010). 'Do theories of organizations progress?' Organizational Research Methods, 13, 690-709.

Davis, G. F. and Marquis, C. (2005). 'Prospects for organization theory in the early twenty-first century: Institutional fields and mechanisms'. Organization Science, 16, 332-43.

Farjoun, M. and Starbuck, W. H. (2007). 'Organizing at and beyond the limits'. Organization Studies, 28, 541-66.

Feldman, M. S. (2000). 'Organizational routines as a source of continuous change'. Organization Science, 11, $611-29$.

Festinger, L. (1957). A Theory of Cognitive Dissonance. Stanford, CA: Stanford University Press.

Fine, G. A. (1991). 'On the macrofoundations of microsociology: Constraint and the exterior reality of structure'. Sociological Quarterly, 32, 161-77.

Glassman, R. B. (1973). 'Persistence and loose coupling in living systems'. Systems Research and Behavioral Science, 18, 83-98.

Hutchins, J. G. B. (1960). 'Reviewed works: Higher education for business by Robert A. Gordon, James E. Howell; The education of American business men: A study in university-college programs in business administration by Frank C. Pierson'. Administrative Science Quarterly, 5, 279-95.

James, W. (1987). Writings 1902-1910. New York: Library of America.

Kahneman, D. (2003). 'Maps of bounded rationality: Psychology for behavioral economics'. American Economic Review, 93, 1449-75.

Kilduff, M. (1993). 'Deconstructing organizations'. Academy of Management Review, 18, 13-31.

Koch, S. E. (1959). Psychology: A Study of a Science. New York: McGraw Hill.

Lindzey, G. E. (1954). Handbook of Social Psychology. Reading, MA: Addison-Wesley.

March, J. G. (2008). Explorations in Organizations. Stanford, CA: Stanford University Press.

March, J. G. and Simon, H. A. (1958). Organizations. New York: Wiley.

Merton, R. K. (1948). 'The self-fulfilling prophecy'. The Antioch Review, 8, 193-210.

Merton, R. K. (1998). On the Shoulders of Giants: A Shandean Postscript. Chicago, IL: University of Chicago Press.

Orton, J. D. and Weick, K. E. (1990). 'Loosely coupled systems: A reconceptualization'. Academy of Management Review, 15, 203-23.

Simon, H. A. (1962). 'The Architecture of complexity'. Proceedings of the American Philosophical Society, 106, 467-82.

Stinchcombe, A. (1982). 'Should sociologists forget their mothers and fathers?' The American Sociologist, 17, $2-11$.

Thoenig, J. C. (1998). 'Essai: How far is a sociology of organizations still needed?' Organization Studies, 19, 307-20.

Turner, B. A. and Pidgeon, N. F. (1997). Man-Made Disasters, 2nd edition. Oxford: ButterworthHeinemann.

Weick, K. E. (1979). The Social Psychology of Organizing, 2nd edition. Reading, MA: Addison-Wesley.

Whyte, W. F. (1948). 'The social structure of the restaurant'. American fournal of Sociology, 54, 302-10.

Whyte, W. H Jr. (1956). The Organization Man. New York: Simon \& Schuster. 